\title{
Evaluation of some parameters of the interaction between detonating explosive charge and environment
}

\author{
Yuri Masaev ${ }^{1^{*}}$, and Vladislav Masaev ${ }^{1}$ \\ ${ }^{1}$ T.F. Gorbachev Kuzbass State Technical University, 650000, 28 Vesennaya Str., Kemerovo, Russia
}

\begin{abstract}
Both strain waves, generated by the shock wave, and expanding gaseous products of the explosion contribute to the destruction of the rocks. The role of these factors is especially obvious at explosion of soft and moderately hard rocks. The article considers some aspects of the phenomena accompanying the explosion of the detonating explosive charge on example of the unworked coal.
\end{abstract}

It is known that both strain waves generated by shock wave, as well as expanding gaseous explosion products are involved in the rock destruction. The role of these factors is especially evident at explosion of soft and moderately hard rocks. Therefore, it is expedient to consider some aspects of the phenomena accompanying charge explosion on example of the unworked coal. For that purpose, we will use calculation scheme based on the equations of F. A. Baum, K. P. Stanyukovich, S. G. Andreev, etc. [1-5].

In conformity with the modern concepts, strain waves and detonation products take part in the destruction of the unworked coal by explosion. The role of the strain wave formed at the initial stage of the explosion, is reduced to the fact that during its propagation, formation of fracture systems follows, the further growth and separation of which is due to the subsequent expansion of the explosive gases.

In the immediate vicinity of the charge, rock undergoes plastic deformations and intensive crushing, and due to this, the initial charge chamber volume increases. Motion of the charge chamber walls stops when pressure of the detonation products reaches the temporary strength limit of the unworked coal.

The law of the interface motion 'detonation products - environment' is described by the F. A. Baum equation:

$$
\frac{d U^{2}}{d r}+\frac{3 U^{2}}{r}=\frac{2 P_{1}}{\rho_{a}} \cdot \frac{r_{\mathrm{K}}^{3 \gamma}}{r^{3(\gamma+1)}}-\frac{2 P_{a}}{\rho_{a}^{r}}
$$

The solution of which is an expression allowing you to determine the interface motion

\footnotetext{
* Corresponding author: myua.spssh@,kuzstu.ru
} 
for any moment in time.

$$
U=\frac{d r}{d t}=\sqrt{\left[U_{\mathrm{K}}^{2}+\frac{2}{3(\gamma-1)} \cdot \frac{P_{\mathrm{K}}}{3 \rho_{a}}+\frac{2 P_{a}}{3 \rho_{a}}\right]\left(\frac{r_{\mathrm{K}}}{r}\right)^{3}-\left[\frac{2}{3(\gamma-1)} \cdot \frac{P_{\mathrm{K}}}{\rho_{a}}\left(\frac{r_{\mathrm{K}}}{r}\right)^{3 \gamma}+\frac{2 P_{a}}{3 \rho_{a}}\right]}
$$

To determine the expansion time of the charge chamber boundary, it is required to integrate the expression (2) within the range from the initial $r 1$ to the final $r 2$ of the radii of the gas cavity, i.e.

$$
t=\int_{r_{1}}^{r_{2}} \frac{d r}{\sqrt{\left[U_{\mathrm{K}}^{2}+\frac{2}{3(\gamma-1)} \cdot \frac{P_{\mathrm{K}}}{\rho_{a}}+\frac{2 P_{a}}{3 \rho_{a}}\right]\left(\frac{r_{\mathrm{K}}}{k}\right)^{3}-\left[\frac{2}{3(\gamma-1)} \cdot \frac{P_{\mathrm{K}}}{\rho_{a}}\left(\frac{r_{\mathrm{K}}}{r}\right)^{3 \gamma}+\frac{2 P_{a}}{3 \rho_{a}}\right]}}
$$

where $P_{a}$ - air pressure; $\rho_{a}$ - environment density; $\gamma$ - isentropic exponent; $r$ - cavity radius; $U_{\mathrm{K}}, P_{\mathrm{K}}, J_{\mathrm{K}}-$ velocity, explosion products pressure, and radius at any intermediate point, respectively; $r_{\mathrm{H}}-$ charging cavity initial radius.

The following alphabetical symbols are accepted in integrand $r_{\mathrm{K}} \approx 2 r_{\mathrm{H}}$ assuming that starting from this distance, the expansion of the gas cavity in the unworked coal is similar to the expansion of the ideal gas in an incompressible liquid $[2,6,7,14,15]$.

Prior to determining pressure $P_{k}$, corresponding to the radius of the charge chamber $r_{\mathrm{K}} \approx$ $2 r_{\mathrm{H}}=4.4 \mathrm{~cm}$, it is necessary to select the isentropy branch, according to which calculation should be made. To do this, let's set the radius of the cavity expansion corresponding to pressure $P^{*}=2000 \mathrm{~kg} / \mathrm{cm}^{2}$.

Prior to determining pressure corresponding to the charge chamber radius, it is essential to select the isentropy branch, according to which the calculation should be made. For this, radius of the cavity expansion corresponding to the pressure $\mathrm{kg} / \mathrm{cm}^{2}$ should be set.

$$
r^{*}=\sqrt{\left(\frac{P_{\mathrm{H}}}{P^{*}}\right)^{\frac{1}{3}}}=3,3 \mathrm{~cm}
$$

then, taking $\gamma=\frac{5}{6}$, we will get

$$
\frac{P_{\mathrm{K}}}{P^{*}}=\left(\frac{V^{*}}{V_{\mathrm{K}}}\right)^{\gamma} \text {, or } P_{\mathrm{K}}=P^{*}\left(\frac{V^{*}}{V_{\mathrm{K}}}\right)^{\gamma}=P_{\mathrm{K}}^{*}\left(\frac{r^{*}}{r_{\mathrm{K}}}\right)^{2 \gamma}=2000\left(\frac{3,3}{4,4}\right)^{\frac{12}{5}}=1050 \mathrm{~kg} / \mathrm{cm}^{2}
$$

To calculate $U_{\mathrm{\kappa}}$, corresponding to the distance $r_{\mathrm{K}}$ we use F. A. Baum expression [2]:

$$
U_{\mathrm{\kappa}}=\sqrt{\frac{2 P_{0}}{2 \rho_{a}}\left[\left(\frac{r_{\text {пр }}}{r_{\mathrm{K}}}\right)^{3}-1\right]}
$$

where $\rho_{a}-$ mass environment density. At the specific coal weight is equal to 1.25 $\mathrm{gr} / \mathrm{cm}^{3}$,

$$
\rho_{a}=\frac{1,25}{980}=1,28 \cdot 10^{-3} \mathrm{gr} \cdot \mathrm{sec}^{2} / \mathrm{cm}^{4}
$$

Let's determine the limit radius of the cavity expansion $r_{\text {пр }}$. 
For the typical high-explosive charges, expansion of the explosion products to pressurer $P^{*}=2000 \mathrm{~kg} / \mathrm{cm}^{2}$ is according to the law

$$
P V^{3}=\text { const or } P_{\mathrm{H}} V_{0}^{3}=P^{*} V^{* 3},
$$

where $V^{*}$ - volume corresponding to pressure $P^{*} ; V_{0}$ - initial volume of the explosion products, equal to volume of the explosive charge; $K=3$-isentropic exponent.

After pressure has dropped to $2000 \mathrm{~kg} / \mathrm{cm}^{2}$, the further expansion of the gases to atmospheric pressure follows a pattern:

$$
P V^{3}=\text { const } \text { or } P^{*} V^{* 3}=P_{a} V_{a}^{\gamma},
$$

where $\gamma=1.2 \div 1.4$ - ratio of heat capacities at constant pressure and volume.

The conjugation of two isentropes at $2000 \mathrm{~kg} / \mathrm{cm}^{2}$ pressure gives a new form of the isentrope as:

$$
\frac{V_{a}}{V_{0}}=\left(\frac{P_{\mathrm{H}}}{P *}\right)^{\frac{1}{3}} \cdot\left(\frac{P *}{P^{a}}\right)^{\frac{1}{\gamma}}
$$

reflecting the two stages of expansion of the explosion products.

The average pressure of the detonation products is determined by:

$$
P_{\mathrm{H}}=\frac{\rho_{0} D^{2}}{8}
$$

where $\rho_{0}=\frac{\gamma_{0}}{g}-$ massive explosive density, $\mathrm{gr} \cdot \mathrm{sec}^{2} / \mathrm{cm}^{4} ; D$ - detonating rate, $\mathrm{cm} / \mathrm{sec}$; $\gamma_{0}$ - weight explosive density, $\mathrm{gr} / \mathrm{cm}^{3} ; g$ - free fall acceleration, $\mathrm{cm} / \mathrm{sec}^{2}$.

Should we take the value of the detonating rate as of $4000 \mathrm{~m} / \mathrm{sec}$ (which corresponds to the ammonite PZHV-20), then at the weight density of the explosive $\gamma_{0}=1.1 \mathrm{gr} / \mathrm{cm}^{3}\left(\rho_{0}=0.0012\right.$ $\mathrm{gr} \cdot \mathrm{sec}^{2} / \mathrm{cm}^{4}$ )

$$
P_{\mathrm{H}}=\frac{0,0012\left(4 \cdot 10^{5}\right)}{8}=22400 \mathrm{~kg} / \mathrm{cm}^{2},
$$

For elongated charges, we can approximately assume that the expansion volume is directly proportional to the square of the charge radius (since $V_{0}=\pi R_{\text {зар }}^{2} \cdot l_{\text {зар }}$,

$$
\left.V_{a} \approx \pi R_{\text {пр }}^{2} \cdot l_{\text {зар }}, \text { то } \frac{V_{a}}{V_{0}}=\left(\frac{R_{\text {пр }}}{R_{\text {зар }}}\right)^{2}\right) .
$$

Considering that limit radius of the cavity expansion is limited by the equality of gas pressure at this stage and environment resistance, and assuming, as per to F. A. Baum, that the zone of maximum expansion of the detonation products, under all other equal conditions, should be determined by yield strength, the value of which for most rocks is

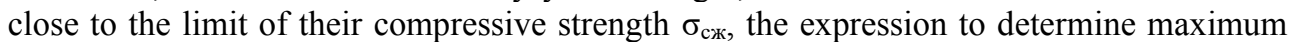
radius of the gas cavity expansion is written as:

$$
\frac{V_{\text {пр }}}{V_{\text {н }}}=\frac{r_{\text {пр }}^{2}}{r_{\mathrm{H}}^{2}}=\left(\frac{P_{\mathrm{H}}}{P *}\right)^{\frac{1}{3}} \cdot\left(\frac{P *}{\sigma_{\text {сж }}}\right)^{\frac{1}{\gamma}}
$$


FOR $\sigma_{\text {сж }}=102 \mathrm{~kg} / \mathrm{cm}^{2}$ we will have:

$$
\begin{aligned}
& \frac{r_{\text {пр }}^{2}}{r_{\mathrm{H}}^{2}}=\left(\frac{22400}{2000}\right)^{\frac{1}{3}} \cdot\left(\frac{2000}{102}\right)^{\frac{5}{6}}=26,4 \\
& r_{\text {пр }}=r_{\text {н }} \sqrt{26,4=2,2 \sqrt{26,4}}=11,3 \mathrm{cM}
\end{aligned}
$$

$P_{a}$ - gas pressure meeting to the strength resistance of the environment at the maximum radius of expansion

$$
2 P_{a}=\sigma_{\text {сж }}=102 \mathrm{~kg} / \mathrm{cm}^{2}
$$

Substituting numerical values $P_{a}, \rho_{a}, r_{\text {пр }}$ and $r_{\mathrm{K}}$ in expression (4), we'll get $U_{\mathrm{\kappa}}=290$ $\mathrm{m} / \mathrm{sec}$.

The integral (3) must be calculated within the limits from $r_{\mathrm{K}}$ to $r_{\text {пр }}$, neglecting expansion time to a distance, less than $r_{\mathrm{K}}$.

Thus, to calculate time $t$ we have:

$$
\begin{array}{lcc}
P_{a}=\sigma_{\text {сж }}=102 \cdot 10^{3} \mathrm{~kg} / \mathrm{cm}^{2} ; & & \rho_{a}=1,28 \cdot 10^{-3} \mathrm{gr} \cdot \mathrm{sec}^{2} / \mathrm{cm}^{4} \\
P_{\mathrm{K}}=1050 \cdot 10^{3} \mathrm{~kg} / \mathrm{cm}^{2} ; & U_{\mathrm{K}}=290 \cdot 10^{2} \mathrm{~cm} / \mathrm{sec} \\
\gamma=1,2 \mathrm{gr} / \mathrm{cm}^{3} ; & r_{\mathrm{K}}=4,4 \mathrm{~cm} ; & r_{\text {пр }}=11,3 \mathrm{~cm} .
\end{array}
$$

It should be noted that hereinafter the distances $\left(r^{*}, r_{\mathrm{K}}, r_{\text {пр }}\right.$ etc.) are counted from the initial boundary of the charge chamber.

In order to calculate the integral by the approximate method, we simplify (3) numerical values by substituting:

$$
t=\int_{r_{\kappa}}^{r_{\mathrm{n}}} \frac{d r}{\sqrt{361 \cdot 10^{7}\left(\frac{r_{\mathrm{K}}}{k}\right)^{3}-\left[273 \cdot 10^{7}\left(\frac{r_{\mathrm{K}}}{r}\right)^{3 \gamma}+5,3 \cdot 10^{7}\right]}}
$$

To provide computational operations, a special table was made, where the time values on the segments inside the integration limit are indicated $t_{i}^{\prime}$ and $t_{i}^{\prime \prime}$. After summing the values $t_{i}^{\mathrm{cp}}$ on the entire integration limit, the total expansion time of the gas cavity will be 1367 microseconds. Creating the time calculation table made it possible to clarify the boundary of the expansion zone, which is located at $15.45 \mathrm{~cm}$ distance from the original wall of the charge chamber. The full radius of the zone, considering the size of the charge chamber $R_{\text {пр }}=17.65$ $\mathrm{cm} \approx 18 \mathrm{~cm}$. Should gas leakage into the cracks is excluded during its expansion, the calculated size of the cavity can take place.

Practically, from the moment of the detonation products expansion, followed by the blast wave propagation, there is a formation of cracks at velocity not exceeding 0.4 of the blast wave velocity $\left(V_{\text {тр }} \leq 0,4 C_{\mathrm{p}}\right)$. At the same time, detonation products tend to penetrate into the resulting cracks, consequently, there should be a rapid pressure drop. However, the limiting radius of the cavity will be determined by the equality of the strength resistance of the environment and final pressure of the gases $\left(\sigma_{\mathrm{c} *}=P_{a}\right)$, even so. Thus, the equilibrium size of the gas cavity due to the gas leakage into the cracks should be less than $R_{\text {пр }}$. Since the interface motion velocity of the expansion zone is significantly less than the velocity of the gases in cracks, then at moving by cavity of finite dimensions, the gases will have time 
to spread through the cracks to a longer distance $R_{\mathrm{T}}^{\Gamma}$. It can be assumed that the pressure of the detonation products at this distance will be equal to the pressure in the cavity and also equal to $P_{a}$.

For an approximate assessment of the distance value $R_{\mathrm{T}}^{\Gamma}$, let's use the following simplified scheme for calculation.

1. Due to the action of the blast wave, a uniformly distributed system of the radial cracks occurs around the charge chamber.

2. When gases penetrate, the cracks take a wedge-shaped shape in the cavity perpendicular to the axis of the hole. Herewith, the width of all cracks at an equal distance from the charge is the same.

A series of the conducted studies in the unworked coal with PZHV-20 ammonite indicates that the maximum diameter ( $Д_{п р}^{\phi}$ ) of the resulting cavities does not exceed 22-26 $\mathrm{cm}$. Should we proceed from the obtained expansion rates of the gas cavity, found for the case of no gas leakage into the cracks, then the average actual time for the cavity formation up to $22 \mathrm{~cm}$ diameter will be $620 \mathrm{~ms}$. At the crack propagation velocity $V_{\text {тр }}=0.4 C_{\mathrm{p}}\left(V_{\text {тр }}\right.$ $744 \mathrm{~m} / \mathrm{sec}$ at $C_{\mathrm{p}}=1860 \mathrm{~m} / \mathrm{sec}$ ), the radius of the crack formation during this time will be 46 $\mathrm{cm}$ or $25.6 r_{\text {зар. }}$.

As per G. I. Pokrovsky [3], angle between any two adjacent radial cracks can be determined from the expression:

$$
\alpha \approx \frac{V_{\text {кр }}}{V_{r}}, \text { рад., }
$$

where $V_{r}$ - rock displacement rate at distance $r$ from explosion site; $V_{\text {кр }}-$ critical rock destruction rate.

For coals, the dependence of the displacement velocity from the distance is approximated by the expression:

$$
V_{r}=\frac{A}{r^{n}},
$$

where $A=2.7 \cdot 10^{6} ; n=2.6 ; \bar{r}$ - reduced distance equal to ratio of the actual distance to charge radius.

$$
\text { At } \bar{r}=25,6 \quad V_{r}=\frac{2,7 \cdot 10^{6}}{25,6^{2,6}}=550 \mathrm{~cm} / \mathrm{sec} .
$$

Critical rate of rock destruction is determined by:

$$
V_{\text {кр }} \approx \frac{\sigma_{\mathrm{p}}}{E} \cdot C_{\mathrm{p}},
$$

where $C_{\mathrm{p}}-$ velocity of the longitudinal blast wave propagation; $\sigma_{\mathrm{p}}-$ tensile rock strength; $E$-rock elastic modulus.

Based on the accepted average values of coals $C_{\mathrm{p}}=1860 \mathrm{~m} / \mathrm{sec}, \sigma_{\mathrm{p}}=1.8 \mathrm{~kg} / \mathrm{cm}^{2} E=$ $0.350 \cdot 10^{5} \mathrm{~kg} / \mathrm{cm}^{2}$, the critical velocity will be:

$$
V_{\text {кр }}=\frac{186 \cdot 10^{3} \cdot 1,8}{0,350 \cdot 10^{5}}=9,56 \mathrm{M} / \mathrm{c} .
$$


Then angle between the adjacent cracks will be equal to:

$$
\alpha=\frac{9,56}{590}=1,62 \cdot 10^{-2} \text { рад. }
$$

Or considering that 1 radian is equal to $57.3^{\circ}$ we will get $\alpha \approx 0.93^{\circ}$.

Thus, at $25.6 r_{\text {пр }}$ distance, at an explosion, there should be $\mathrm{K}=360^{\circ} / 0,93^{\circ}=390$ cracks.

Assuming that the increase in the circumference of the charge chamber during its expansion from the initial diameter $(4.4 \mathrm{~cm})$ to the final one $(22 \mathrm{~cm})$ is due to the expansion of the resulting cracks, we will obtain the average width of the crack base:

$$
\delta=\frac{\pi Д_{\mathrm{K}}-\pi Д_{\text {нач }}}{K}=0,14 \mathrm{~cm} .
$$

Then the volume of detonation products penetrated into the cracks can be defined as:

$$
V_{\mathrm{T}}^{\mathrm{\Gamma}}=\frac{1}{2} K \delta R_{\mathrm{T}}^{\mathrm{\Gamma}} l_{\text {зар }},
$$

where $R_{\mathrm{T}}^{\Gamma}$ - penetration distance of the detonation products into cracks, from the final boundary of the gas cavity during its expansion; $l_{3 \text { ар }}$ - charge chamber length.

The total volume occupied by the detonation products at the moment of the gas cavity expansion completion at pressure of $P_{a}$ is equal to:

$$
V_{\text {об }}=\pi\left(R_{\text {пр }}^{\phi}\right)^{2} l_{\text {зар }}+\frac{1}{2} K \delta R_{\mathrm{T}}^{\Gamma} l_{\text {зар }} \text {. }
$$

Since the gas cavity formation proceeding without leakage of the detonation products into the cracks, is also completed at pressure $P_{a}$, which characterizes the strength properties of the environment, we can make the following equation:

$$
\begin{gathered}
\pi R_{\text {пр }}^{2} l_{\text {зар }}=\pi\left(R_{\text {пр }}^{\phi}\right)^{2} l_{\text {зар }}+\frac{1}{2} K \delta R_{\mathrm{T}}^{\text {г } l_{\text {зар }} .} \\
\text { Where, } R_{\mathrm{T}}^{\text {г }}=\frac{2 \pi\left[R_{\text {пр }}^{2}-\left(R_{\text {пр }}^{\phi}\right)^{2}\right]}{K \delta}=\frac{2 \cdot 3,14\left(18^{2}-11^{2}\right)}{390 \cdot 0,14}=23 \mathrm{~cm} .
\end{gathered}
$$

It means that during the gas cavity expansion to $22 \mathrm{~cm}$ of diameter, equal to 620 microseconds, the explosion products propagating through the cracks will be ahead of its final boundary by $23 \mathrm{~cm}$. At the same time, the path traveled by the gases during this time, taking into account the initial size of the charge chamber, will be $31.8 \mathrm{~cm}$ that corresponds to the average velocity $5410 \mathrm{~m} / \mathrm{sec}$.

To determine breakthrough time of the detonation products into the bottom-hole area, it is required to establish the regularity of the gas flow velocity drop with an increase in the line of the least resistance. So, we have created a table of the source data (Table 1). 
Table 1.

\begin{tabular}{|c|c|c|c|}
\hline$Q_{\text {charge, }}, \mathrm{kg}$ & $L_{\text {charge, }} \mathbf{m}$ & $X, \mathbf{m}$ & $l_{\mathrm{mI},}, \mathrm{m}$ \\
\hline 0.600 & 0.54 & \multirow{4}{*}{0.5} & 1.04 \\
\hline 0.900 & 0.81 & & 1.31 \\
\hline 1.200 & 1.08 & & 1.58 \\
\hline 1.500 & 1.35 & & 1.85 \\
\hline 0.600 & 0.54 & \multirow{4}{*}{1.0} & 1.54 \\
\hline 0.900 & 0.81 & & 1.81 \\
\hline 1.200 & 1.08 & & 2.08 \\
\hline 1.500 & 1.35 & & 2.35 \\
\hline 0.600 & 0.54 & \multirow{4}{*}{1.5} & 2.04 \\
\hline 0.900 & 0.81 & & 2.31 \\
\hline 1.200 & 1.08 & & 2.58 \\
\hline 1.500 & 1.35 & & 2.58 \\
\hline
\end{tabular}

In accordance with the earlier verified calculation, we assume that at $0.318 \mathrm{~m}$ distance from the charge chamber, gas velocity in cracks will be $510 \mathrm{~m} / \mathrm{sec}$.

Gas motion in the channel is described by a system of Euler differential equations:

$$
\left\{\begin{array}{c}
\frac{\partial U}{\partial t}+U \frac{\partial U}{\partial r}+\frac{1}{\rho} \frac{\partial \rho}{\partial r}=0 \\
\frac{\partial l_{\mathrm{n}} \rho}{\partial t}+U \frac{\partial l_{\mathrm{n}} \rho}{\partial r}+\frac{\partial U}{\partial r}=0 \\
\frac{\partial P \rho^{\gamma}}{\partial t}+U \frac{\partial P \rho^{-\gamma}}{\partial r}=0
\end{array}\right.
$$

where $U$ - gas flow rate; $\rho$ - gas density; $P$ - gas pressure; $t$ - gas flow time; $r$ distance traveled by the gas flow leading edge.

Upon a number of substitutions and transformations, we solve the system (9) and finally get:

$$
U=\frac{C}{(r-U t)^{2}}
$$

To calculate velocity of gases at each moment of time we are interested in, we introduce the following notation:

$$
U_{\mathrm{cp}}=\frac{1}{2}\left(U_{\mathrm{H}}+U_{\mathrm{\kappa}}\right), \quad t_{\mathrm{K}}=\frac{r_{\mathrm{K}}}{U_{\mathrm{cp}}},
$$

where $U_{\mathrm{H}}$ - initial gas velocity in some area; $U_{\mathrm{K}}, t_{\mathrm{K}}, r_{\mathrm{K}}$ - final values of velocity, time, and distance.

Considering the entered notation, we will have:

$$
U=\frac{C}{\left(r_{\mathrm{K}}-U_{\mathrm{K}} t_{\mathrm{K}}\right)^{2}}=\frac{C}{\left[r_{\mathrm{K}}-\left(2 U_{\mathrm{cp}}-U_{\mathrm{H}}\right) \cdot \frac{r_{\mathrm{K}}}{U_{\mathrm{cp}}}\right]^{2}}=\frac{C}{\left(\frac{U_{\mathrm{H}}}{U_{\mathrm{cp}} \cdot r_{\mathrm{K}}-r_{\mathrm{K}}}\right)^{2}}=\frac{C}{r_{\mathrm{K}}^{2}}\left(\frac{U_{\mathrm{H}}}{U_{\mathrm{cp}}}-1\right)^{2}
$$

or 


$$
2 U_{\mathrm{cp}}-U_{\mathrm{H}}=\frac{C}{r_{\mathrm{\kappa}}^{2}\left(\frac{U_{\mathrm{H}}}{U_{\mathrm{cp}}}-1\right)^{2}}
$$

Let's define value of the integration constant ' $\mathrm{C}$ '.

From (11) we have: $C=U_{\mathrm{K}} r_{\mathrm{K}}^{2}\left(\frac{U_{\mathrm{H}}}{U_{\mathrm{cp}}}-1\right)^{2}$.

To calculate initial velocity in the area of $0-0.318 \mathrm{~m}$, it is required to determine the detonation products velocity of the $V \mathrm{y}$ at the charge surface.

$$
V=\frac{W}{\sin \varphi},
$$

where $W$ - gas velocity moving behind the detonation front along the charge axis; $(\varphi-$ angle between perpendicular to the charge axis and direction of the maximum energy flux density of gases,

$$
\varphi-\operatorname{arctg} \frac{K-1}{2 K}, K=3, \varphi=18^{\circ}, W=\frac{D}{K+1}=1000 \mathrm{~m} / \mathrm{sec},
$$

at $D=4000 \mathrm{~m} / \mathrm{sec}$ (PZHV-20 ammonite).

Then velocity at the charge surface will be determined as:

$$
V=\frac{1000}{\sin 18^{\circ}}=3240 \mathrm{~m} / \mathrm{sec}
$$

As distance increases, the gas velocity decreases rapidly, approximately according to the law:

$$
\frac{U_{\mathrm{x}}}{V} \approx\left(\frac{r_{0}}{r_{\mathrm{x}}}\right)^{4}
$$

where $r_{0}$ - explosive charge radius.

It should be noted that this dependence is valid only for the initial stage, when gas expansion obeys the isentrope $P=A \rho^{3}$. Pursuant to the law, at the moment when the gases reach the walls of the hole

$$
U=V\left(\frac{r_{0}}{r_{\mathrm{x}}}\right)^{4}=3240\left(\frac{18}{22}\right)^{4} \approx 1460 \mathrm{~m} / \mathrm{sec} .
$$

Then for the initial area of explosive gas propagation $0-0.318 \mathrm{~m}$ we have: $U_{\mathrm{H}}=1460$ $\mathrm{m} / \mathrm{sec} ; \quad U_{\mathrm{\kappa}}=510 \mathrm{~m} / \mathrm{sec} ; \quad U_{\mathrm{cp}},=385 \mathrm{~m} / \mathrm{sec}$.

Substituting the obtained values, we determine ' $\mathrm{C}$ ':

$$
C=510 \cdot 0,1\left(\frac{1460}{885}-1\right)^{2}=2,14 .
$$

Transforming equation (12), we get: 


$$
4 U_{\mathrm{H}}^{2} U_{\mathrm{cp}} r_{\mathrm{K}}^{2}-5 U_{\mathrm{H}} U_{c p}^{2} r_{\mathrm{K}}^{2}+2 U_{c p}^{3} r_{\mathrm{K}}^{2}-U_{\mathrm{H}}^{3} r_{\mathrm{K}}^{2}=C U_{\mathrm{cp}}^{2}
$$

Let's determine values of the coefficient at $U_{\mathrm{cp}}$ and absolute term for $r_{\mathrm{K}}=0,5$.

$$
\begin{gathered}
4 U_{\mathrm{H}}^{2} U_{\mathrm{cp}} r_{\mathrm{K}}^{2}=4 \cdot 510^{2} \cdot 0,5^{2}=256000 \\
5 U_{\mathrm{H}} U_{c p}^{2} r_{\mathrm{K}}^{2}=5 \cdot 510^{2}=636,2 r_{\mathrm{K}}^{2} 0,50 \\
U_{\mathrm{H}}^{3} r_{\mathrm{K}}^{2}=510^{3} \cdot 0,5^{2}=33,2 \cdot 10^{6}
\end{gathered}
$$

Substituting the obtained coefficients, we get

$$
U_{\mathrm{cp}}^{3}-127,4 U_{\mathrm{cp}}^{2}+520000 U_{\mathrm{cp}}-66,3 \cdot 10^{6}=0
$$

After the calculations, we obtain $U_{\mathrm{cp}} \approx 445 \mathrm{~m} / \mathrm{sec}$.

Since on the $0.318-0.5 \mathrm{~m}$ section initial velocity, which is the final velocity on the $0-$ $0.318 \mathrm{~m}$ section, is equal to $510 \mathrm{~m} / \mathrm{sec}$, the final velocity will be:

$$
U_{\mathrm{K}}=2 U_{\mathrm{cp}},-U_{\mathrm{H}}=890-510=380 \mathrm{~m} / \mathrm{sec} .
$$

Afterward, again substituting the obtained value $U_{\mathrm{K}}$ (which in the next section of $0.5-$ $1.0 \mathrm{~m}$ is the initial $-U_{\mathrm{H}}$ ) in (13) and solving the resulting equation, we determine

$$
U_{\mathrm{cp}}=445 \mathrm{M} / \mathrm{c}, \quad U_{\mathrm{\kappa}}=274 \mathrm{M} / \mathrm{c} .
$$

For the last section $1.0-1.5 \mathrm{~m}$

$$
U_{\mathrm{cp}} \approx 237 \mathrm{M} / \mathrm{c}, \quad U_{\mathrm{\kappa}}=200 \mathrm{~m} / \mathrm{sec} .
$$

Thus, the gas velocity in individual sections has the following values (Table 2)

Table 2.

\begin{tabular}{|c|c|c|c|}
\hline $\begin{array}{c}\text { Path section covered } \\
\text { by gases, } \mathbf{m}\end{array}$ & $\begin{array}{c}\text { Initial gas velocity on } \\
\text { section, } \mathbf{m} / \mathbf{s e c}\end{array}$ & $\begin{array}{c}\text { Final gas velocity on } \\
\text { section, } \mathbf{m} / \mathbf{s e c}\end{array}$ & $\begin{array}{c}\text { Average gas velocity } \\
\text { on section, m/sec }\end{array}$ \\
\hline $0-0.318$ & 1460 & 510 & 885 \\
\hline $0.318-0.50$ & 510 & 380 & 445 \\
\hline$-0.50-1.00$ & 380 & 274 & 322 \\
\hline $1.00-1.50$ & 274 & 200 & 287 \\
\hline
\end{tabular}

Based on the obtained average velocities, the gas passage time of the specified sections, with some approximation, will be $1 \mathrm{~ms}, 3 \mathrm{~ms}$, and $6 \mathrm{~ms}$, respectively.

\section{References}

1. F.A. Baum, L.P. Orlenko, K.P. Stanyukovich, Physics of Explosion (Nauka, Moscow, 1975)

2. F.A. Baum, K.P. Stanyukovich, B.I. Shechter, Physics of Explosion (Fizmatiz, Moscow, 1953)

3. K.P. Stanyukovich, Unsteady Motion of the Continuous Environment (Nauka, Moscow, 1971)

4. S.G. Andreev, L.P. Orlenko. Physics of Explosion (Fizmatlit, Moscow, 2002)

5. S.G. Andreev, L.P. Orlenko, Physics of Explosion (Fizmatlit, Moscow, 2004) 
6. G.M. Lyakhov, Fundamentals of Explosion Dynamics in Soils and Liquid Environments (Nedra, Moscow, 1964)

7. G.M. Lyakhov, Fundamentals of Explosion Dynamics in Soils Souls and Rocks (Nedra, Moscow, 1974)

8. F.A. Baum, Collection Explosive business (Gosgortehizdat, Moscow 1963)

9. L.P. Orlenko, Physics of Explosion and Impact (Fizmatlit, Moscow, 2006)

10. G.I. Pokrovskiy, I.S. Fyedorov, The Effects of Impact and Explosion in Deformable Environments (State Ed. literature on builds. materials, Moscow, 1957)

11. A.N. Hanukaev, Physical Processes at Rock Breaking (Nedra, Moscow, 1974)

12. V.N. Mosinets, The Explosion Crushing and Seismic Effect in Rocks (Nedra, Moscow, 1976)

13. K.K. Andreev, A.F. Belyaev, The Explosives Theory (Oborongiz, Moscow, 1960)

14. S.J.K. Furtney, E. Sellers, I. Onederra. Edited by Pradeep K. Singh, Amalendu Sinha. 275 (Leiden, Netherlands, CRC Press, 2013)

15. J.M. Akande, A.I. Lawal, Geomaterials, 3:1. 28 (2013) 